\title{
Activation of Monocytes and Platelets by Monoclonal Antibodies or Malaria- infected Erythrocytes Binding to the CD36 Surface Receptor in vitro
}

\author{
Christian F. Ockenhouse, ${ }^{\star *}$ Cathleen Magowan, ${ }^{*}$ and Jeffrey D. Chulay* \\ *Department of Immunology, Walter Reed Army Institute of Research, Washington, DC 20307-5100; and \\ ${ }^{\ddagger}$ Department of Medicine, Walter Reed Army Medical Center, Washington, DC 20307-5001
}

\begin{abstract}
The CD36 leukocyte differentiation antigen, recognized by MAbs OKM5 and OKM8 and found on human monocytes and endothelial cells, has been implicated as a sequestration receptor for erythrocytes infected with the human malaria parasite Plasmodium falciparum (IRBC). CD36 is also expressed on platelets and appears to be identical to platelet glycoprotein IV. We investigated receptor activation of monocytes and platelets by anti-CD36 MAbs and by IRBC. Incubation of human monocytes with anti-CD36 MAbs or IRBC resulted in stimulation of the respiratory burst as measured by reduction of nitroblue tetrazolium and generation of chemiluminescence. Incubation of human platelets with anti-CD36 MAbs resulted in platelet activation as measured by aggregation or ATP secretion. Activation of monocytes and platelets required appropriate intracellular transmembrane signaling and was inhibited by calcium antagonists or by specific inhibitors of protein kinase $\mathrm{C}$ or guanine nucleotide binding proteins. Soluble CD36 inhibited binding of IRBC to both monocytes and platelets, suggesting that these interactions are mediated by the CD36 receptor. Using a cytochemical electron microscopic technique, the presence of reactive oxygen intermediates was identified at the interface between human monocytes and IRBC. These data provide support for the hypothesis that reactive oxygen intermediates produced by monocytes when IRBC ligands interact with cell surface receptors may play a role in the pathophysiology of falciparum malaria.
\end{abstract}

\section{Introduction}

For many microorganisms, attachment to specific cells and tissues, mediated by ligands that are complementary to host cell receptors, is a critical event that determines pathogenicity. Malaria caused by Plasmodium falciparum is characterized by sequestration of erythrocytes infected with mature trophozoite and schizont stages of the parasite. These infected erythrocytes

Address reprint requests to Dr. J. D. Chulay, Department of Immunology, Walter Reed Army Institute of Research, Washington, DC 20307-5100.

Received for publication 14 June 1988 and in revised form 7 February 1989.

1. Abbreviations used in this paper: $\mathrm{C}+, \mathrm{IRBC}$ with increased cytoadherence; C-, IRBC with decreased cytoadherence; H-7, 1-(5-isoquinolinesulfonyl)-2-methylpiperazine dihydrochloride; IRBC, infected erythrocyte(s); $\mathrm{K}+$, knobby IRBC; $\mathrm{K}-$, knobless IRBC; NBT, nitroblue tetrazolium; TNF, tumor necrosis factor.

J. Clin. Invest.

(C) The American Society for Clinical Investigation, Inc. 0021-9738/89/08/0468/08 \$2.00

Volume 84, August 1989, 468-475
(IRBC) ${ }^{1}$ bind to host endothelium via electron-dense protrusions, commonly referred to as knobs, on the erythrocyte membrane (1). Knobs are not present on erythrocytes infected with immature ring stage parasites, and only at this stage of parasite development do IRBC circulate freely (2-4). Knobpositive $(\mathrm{K}+)$ IRBC have been shown to bind in vitro to human endothelial cells $(5)$, some melanoma cell lines $(6,7)$, human monocytes $(8,9)$, and phorbol ester-differentiated U937 histiocytic lymphoma cells (10).

The pathophysiological significance of IRBC sequestration is complex. Sequestration appears to contribute to parasite survival by allowing nondeformable IRBC to avoid the filtering action of the spleen (11-14). Sequestration may also contribute to host pathology. Sequestration in cerebral postcapillary venules is a uniform feature of fatal cerebral malaria (15, 16) and may be responsible for the central nervous system lactic acidosis that is associated with a fatal outcome (17). In addition, mononuclear phagocytes are often found in regions of sequestered IRBC $(2-4,16,18-20)$, and secretory products released by monocytes and macrophages, including reactive oxygen intermediates and tumor necrosis factor (TNF), may contribute to host pathology $(21,22)$.

The preferential localization of IRBC to vascular endothelium in specific sites within organs such as the brain $(15,16)$, lung $(18)$, kidney $(3,4)$, and placenta $(19,20)$ implies a restricted distribution of cell membrane receptors. We have previously reported that the expression of an $88-\mathrm{kD}$ glycoprotein leukocyte differentiation antigen, defined by MAb OKM5 and designated CD36 (23), correlates with cytoadherence $(9,10)$. MAb OKM5 also inhibits and reverses cytoadherence of IRBC to monocytes, endothelial cells, and C32 melanoma cells (9), suggesting that CD36 may be a malaria sequestration receptor. CD36 has recently been purified from platelets, where it is known as glycoprotein IV (24). Purified CD36 binds with receptor-like specificity to IRBC and inhibits cytoadherence of IRBC to melanoma cells and endothelial cells (25), providing direct evidence in support of the hypothesis that CD36 is a sequestration receptor.

We now report that anti-CD36 MAbs activate human platelets, as measured by aggregation or ATP release, and stimulate human monocytes to release reactive oxygen intermediates, mimicking the effects of $\operatorname{IRBC}(8,26)$. These data suggest a mechanism for specific activation of host inflammatory responses by ligands on the surface of IRBC, and imply that the conformation of these ligands may mimic the antibody combining site of these anti-CD36 MAbs.

\section{Methods}

Materials. MAbs OKM1, OKM5, and OKM8 were gifts from Dr. G. Goldstein and Dr. M. Talle, Ortho Pharmaceutical, Raritan, NJ. MAb OKM5 conjugated to FITC was purchased from Ortho. MAb 2A12, which recognizes a Trypanosoma brucei variable surface glycoprotein, 
was provided by Dr. Ted Hall, Walter Reed Army Institute of Research, Washington, DC. Purified CD36 was a gift of Dr. N. Tandon and Dr. G. A. Jamieson, American Red Cross, Rockville, MD. Aminotriazole, ADP, AA, cerium chloride, cholera toxin, EDTA, glutaraldehyde, horseradish peroxidase type II, 1-(5-isoquinolinesulfonyl)-2methylpiperazine dihydrochloride (H-7), luminol, luciferin-luciferase, nitroblue tetrazolium (NBT), pertussis toxin, thrombin, trypsin, and verapamil were obtained from Sigma Chemical Co., St. Louis, MO. Cell-Tak was obtained from Biopolymers, Inc., Farmington, CT.

Parasites. $P$. falciparum clones ItG2F6 (27) and FCR-3 (28) with the knobby $(\mathrm{K}+)$ phenotype, and a knobless $(\mathrm{K}-)$ line derived from the Uganda Palo Alto/PLF-3 B11 clone (29) were cultured as previously described $(30,31)$. The $\mathrm{K}-$ phenotype was confirmed by electron microscopy and lack of reactivity with a MAb against the knobassociated, histidine-rich protein (MAb 89 , kindly provided by Dr. Diane Taylor, Georgetown University, Washington, DC). ItG2F6 parasites were selected for different adherence phenotypes $(\mathrm{C}+$ or $\mathrm{C}-$ ) by sequential passages of IRBC over monolayers of $C 32$ melanoma cells (32). In brief, IRBC with increased cytoadherence ( $C+$ phenotype) were selected by incubating IRBC with melanoma cells for $1 \mathrm{~h}$, removing nonadherent IRBC, adding fresh uninfected erythrocytes, and culturing overnight to allow merozoite invasion to occur. The parasites used in the present experiments were selected for the $\mathrm{C}+$ phenotype 18 times (P18) or were subclones of parasites selected for the $\mathrm{C}+$ phenotype 31 times (clone 11G). K+ IRBC with decreased cytoadherence (C- phenotype) were selected by collecting nonadherent IRBC after sequential incubations with melanoma cells until no adherent cells were observed by light microscopy. These nonadherent cells were continued in culture. The parasites used in the present experiments were from the ItG2F6 clone, which was selected for the C-phenotype 18 times before subcloning to yield the E8 clone.

For some experiments, $\mathrm{K}+\mathrm{IRBC}$ were enriched by sedimentation of erythrocytes (3\% parasitemia) in gelatin for $1 \mathrm{~h}$ at $37^{\circ} \mathrm{C}$. Erythrocytes remaining in the supernatant (35\% parasitemia) were removed, washed twice in RPMI 1640, and resuspended in complete medium (RPMI 1640 with $25 \mathrm{mM}$ Hepes, $32 \mathrm{mM} \mathrm{NaHCO}$, and $10 \%$ normal human serum).

Cell preparation. Blood was collected into 1:10 vol of $3.8 \%$ sodium citrate. Platelet-rich plasma, obtained by centrifugation at $180 \mathrm{~g}$ for 15 min at room temperature, was kept at room temperature in polypropylene tubes and used within $3 \mathrm{~h}$.

Monocytes were isolated by layering blood onto Ficoll-Hypaque density gradients (Pharmacia Fine Chemicals, Piscataway, NJ) and centrifuging for $25 \mathrm{~min}$ at $600 \mathrm{~g}$ at room temperature. The mononuclear cell-enriched interface was recovered, washed, and resuspended in complete medium. Cells $\left(2.5 \times 10^{6} / \mathrm{ml}\right)$ were plated onto tissue culture flasks and incubated at $37^{\circ} \mathrm{C}$ in $7.5 \% \mathrm{CO}_{2}$. After $2 \mathrm{~h}$, nonadherent cells were aspirated and the remaining attached cells were incubated for $15 \mathrm{~min}$ in $7 \mathrm{mM}$ EDTA at $37^{\circ} \mathrm{C}$. After vigorous pipetting, the recovered cells, $>90 \%$ monocytes by morphologic criteria, were washed and resuspended in complete medium to $2 \times 10^{6} / \mathrm{ml}$.

Chemiluminescence assays. Luminol-dependent chemiluminescence of monocytes in response to anti-CD36 MAbs was performed in a Lumi-aggregometer (Chrono-Log Corp., Havertown, PA) adapted to measure the onset of the respiratory burst in agonist-induced leukocytes (33). Monocytes $\left(2 \times 10^{5}\right.$ in $\left.0.5 \mathrm{ml}\right)$ were suspended in HBSS without phenol red and incubated for $5 \mathrm{~min}$ at $37^{\circ} \mathrm{C}$ in a sample holder containing $10 \mu \mathrm{M}$ luminol and $9 \mathrm{U}$ horseradish peroxidase. Stimuli and inhibitors were pipetted into the magnetically stirred sample, and the chemiluminescence progress curves were plotted on an X-Y recorder.

Luminol-dependent chemiluminescence of monocytes in response to IRBC was measured in a liquid scintillation counter in the off-coincidence mode on the tritium channel. Monocyte monolayers on round glass coverslips were placed into liquid scintillation vials. A stock solution of luminol $\left(2 \times 10^{-3} \mathrm{M}\right.$ in DMSO) was diluted to $2 \times 10^{-5} \mathrm{M}$ in PBS, and $0.5 \mathrm{ml}$ was added to each vial together with $0.5 \mathrm{ml}$ complete medium. The chemiluminescence response was triggered by the addi- tion of $30 \mu \mathrm{l}$ of a $5 \%$ suspension of uninfected erythrocytes or IRBC (FCR-3 strain, enriched to $35 \%$ parasitemia, with or without pretreatment with trypsin at $100 \mu \mathrm{g} / \mathrm{ml}$ ). Vials were counted for $12 \mathrm{~s}$ every 10 min. Results are expressed as net counts per minute (counts per minute in samples with monocytes minus counts per minute in samples without monocytes).

In vitro cytoadherence assay and NBT reduction. Monocytes (2 $\times 10^{5}$ in $0.5 \mathrm{ml}$ ) were pipetted into 24-well tissue culture plates and incubated at $37^{\circ} \mathrm{C}$ in $7.5 \% \mathrm{CO}_{2}$ for $90 \mathrm{~min}$. Medium was aspirated and $250-\mu$ l aliquots of a $2 \%$ suspension of IRBC (3-10\% parasitemia) were added to wells containing monocytes. In some experiments IRBC were incubated with purified CD36 for 30 min before being added to monocytes. After $2 \mathrm{~h}$ unattached erythrocytes were aspirated and the wells rinsed with medium. The remaining IRBC bound to monocytes were fixed in methanol, stained with Giemsa, and counted under a microscope (magnified 1,000 times). At least 100 monocytes were counted and the percentage of cells binding at least one IRBC was calculated. In some experiments NBT $(1 \mathrm{mg} / \mathrm{ml})$ was added simultaneously with the IRBC. In other experiments NBT was added simultaneously with MAbs. Monocytes with and without bound IRBC were scored positive if they contained a blue-black precipitate, indicating reduction of NBT to formazan as a result of respiratory burst activity. In some experiments monocytes were incubated with $\mathrm{H}-7$, pertussis toxin, or cholera toxin for $30 \mathrm{~min}$ before the addition of NBT and IRBC or MAbs. These metabolic inhibitors did not affect the level of cytoadherence of IRBC to monocytes.

Electron microscopy. An ultrastructural cytochemical assay to localize hydrogen peroxide between opposing membranes was performed in samples of IRBC attached to monocytes according to previously described techniques $(34,35)$. Monocyte monolayers were cocultured with IRBC for $40 \mathrm{~min}$ at $37^{\circ} \mathrm{C}$. Nonadherent erythrocytes were then aspirated and the culture plates incubated in a solution of $100 \mathrm{mM}$ Tris, $\mathrm{pH} 7.5,10 \mathrm{mM}$ aminotriazole, $5 \%$ sucrose, and $2 \mathrm{mM}$ cerium chloride. After incubation at $37^{\circ} \mathrm{C}$ for 90 min cells were detached from the wells with a rubber policeman and fixed for $2 \mathrm{~h}$ in $2 \%$ glutaraldehyde, postfixed in osmium tetroxide, dehydrated, and embedded in Epon. Ultrathin sections were mounted on grids and stained with uranyl acetate and lead citrate.

Platelet function studies. Platelet aggregation and ATP secretion in platelet-rich plasma was determined in a Lumi-aggregometer (Chrono-Log Corp.) (36). Platelet aggregation was measured as the percent increase in light transmission after the addition of agonist, or agonist plus inhibitor, to platelet-rich plasma. ATP secretion from platelet storage granules was measured simultaneously by a luciferinluciferase assay. Briefly, $400 \mu \mathrm{l}$ platelet-rich plasma $\left(3 \times 10^{8} / \mathrm{ml}\right)$ was added to magnetically stirred siliconized glass vials and incubated at $37^{\circ} \mathrm{C}$. Luciferin-luciferase $(50 \mu \mathrm{l}$ of a $40 \mathrm{mg} / \mathrm{ml}$ stock solution) and 50 $\mu \mathrm{l}$ of $10 \times$ agonist were added to give a final vol of $500 \mu \mathrm{l}$. In some experiments varying concentrations of $\mathrm{H}-7$, pertussis toxin, or cholera toxin were added $2 \mathrm{~min}$ before addition of agonists. Platelets aggregated normally in response to thrombin, epinephrine, ADP, and AA.

Platelet binding to IRBC. Round glass coverslips were incubated for $20 \mathrm{~min}$ with Cell-Tak $(20 \mu \mathrm{g} / \mathrm{ml}$ in $\mathrm{pH} 9.6$ sodium carbonate buffer) and rinsed with PBS. A 10\% suspension of IRBC (7-9\% parasitemia) was pipetted onto these coverslips and allowed to attach for 30 min, after which BSA (0.2\% in PBS) was added to minimize nonspecific binding. Platelet-rich plasma was suspended for $10 \mathrm{~min}$ in paraformaldehyde ( $1 \%$ in sodium phosphate buffer, pH 7.4), overlayed onto Ficoll-Hypaque, and centrifuged at $2,000 \mathrm{rpm}$ for $25 \mathrm{~min}$ at room temperature. Platelets collected from the interface were washed twice with PBS, resuspended to $\sim 1 \times 10^{8} / \mathrm{ml}$ in PBS, and stored at $4^{\circ} \mathrm{C}$ for up to $1 \mathrm{wk}$. Aliquots $(80 \mu \mathrm{l})$ were pipetted onto coverslips with attached IRBC and incubated at $37^{\circ} \mathrm{C}$. After $1 \mathrm{~h}$ coverslips were gently rinsed with RPMI 1640, fixed with $2 \%$ glutaraldehyde, and stained with Giemsa. At least 100 IRBC were counted to determine the mean $( \pm S D)$ percentage of IRBC binding at least one platelet.

Immunofluorescence. CD36 is detected by immunofluorescence on $\sim 75 \%$ of normal human monocytes $(10,37)$. To detect CD36 on 
platelets, aliquots of platelet-rich plasma, or platelets fixed with formalin, were incubated with FITC-conjugated MAb OKM5 $(10 \mu \mathrm{g} / \mathrm{ml})$ for $30 \mathrm{~min}$ at room temperature, washed, and examined at $1,000 \times$ magnification for surface fluorescence under ultraviolet microscopy.

\section{Results}

Stimulation of monocytes by MAbs to CD36. Anti-CD36 MAbs OKM5 and OKM8 stimulated the respiratory burst in normal human monocytes as measured by both reduction of NBT to formazan (Fig. $1 A$ ) and luminol-dependent chemiluminescence (Fig. $2 A$ ). The respiratory burst was not stimulated by other MAbs of the same isotype, including MAb OKM1 which recognizes the complement receptor $\mathrm{C} 3 \mathrm{bi}$ on the surface of monocytes (38).

Because the respiratory burst depends on activation of membrane-bound NADPH oxidase by protein kinase C (39), we tested whether secretion of reactive oxygen intermediates could be modulated by the protein kinase $\mathrm{C}$ inhibitor $\mathrm{H}-7$. NBT reduction (Fig. $1 B$ ) and chemiluminescence (Fig. $2 B$ ) stimulated by MAb OKM5 were inhibited by $\mathrm{H}-7$ at concentrations $\geq 100 \mu \mathrm{M}$. At $50 \mu \mathrm{M} \mathrm{H}-7$ enhanced chemiluminescence induced by MAb OKM5 (Fig. $2 \mathrm{~B}$ ). The same concentration of $\mathrm{H}-7$ is also known to enhance mitogen-induced activation of murine lymphocytes (40). Both cholera toxin and pertussis toxin, inhibitors of second messenger pathways controlled by the guanine nucleotide binding proteins $\mathrm{Gs}$ and $\mathrm{Gi}$ (41), inhibited NBT reduction of monocytes stimulated with MAb OKM5 (Fig. $1 B$ ).

Activation of platelets by MAbs to CD36. MAbs OKM5 and OKM8 activated normal human platelets as measured by both platelet aggregation (Fig. $3 A$ ) and ATP secretion (Fig. 3 $C$ ) in citrated platelet-rich plasma. MAb-induced platelet activation was dose dependent $(23 \%$ aggregation at $1 \mu \mathrm{g} / \mathrm{ml}$ and $50-60 \%$ aggregation at $\geq 2 \mu \mathrm{g} / \mathrm{ml}$ ).

In citrated platelet-rich plasma CD36 was detected on the surface of platelet aggregates by immunofluorescence with FITC-conjugated MAb OKM5. When platelets were either suspended in EDTA or fixed with formalin before incubation with MAb OKM5, CD36 was detected on the surface of individual platelets by immunofluorescence, but platelet aggregation did not occur. These observations suggest that platelet aggregation induced by MAb OKM5 resulted from agonist-in-
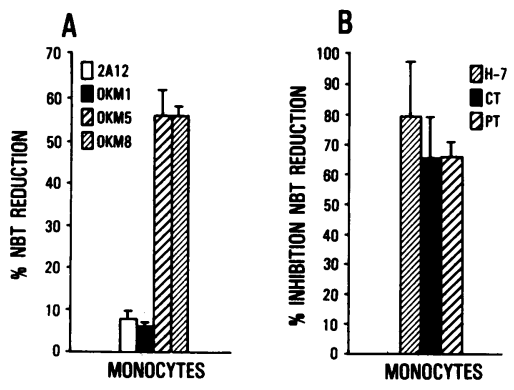

Figure 1. (A) Stimulation of monocyte NBT reduction by anti-CD36 MAbs. Human monocytes attached to coverslips were incubated for $2 \mathrm{~h}$ with NBT and anti-CD36 MAbs (OKM5 or OKM8) or control MAbs (2A 12 or OKM1) at $10 \mu \mathrm{g} / \mathrm{ml}$. Coverslips were fixed, stained, and counted to determine the percentage of monocytes reducing NBT. Results are expressed as mean $\pm \operatorname{SD}(n=4)$. $(B)$ Inhibition of MAb OKM5-induced monocyte NBT reduction by inhibitors of second messengers. Monocytes were incubated as in $A$, but in the presence of the protein kinase $\mathrm{C}$ inhibitor $\mathrm{H}-7(100 \mu \mathrm{M})$ or the guanine nucleotide binding protein inhibitors cholera toxin $(C T)$ or pertussis toxin $(P T)$ at $1 \mu \mathrm{g} / \mathrm{ml}$. Results are expressed as mean percent inhibition $( \pm \mathrm{SE}, n=3)$.
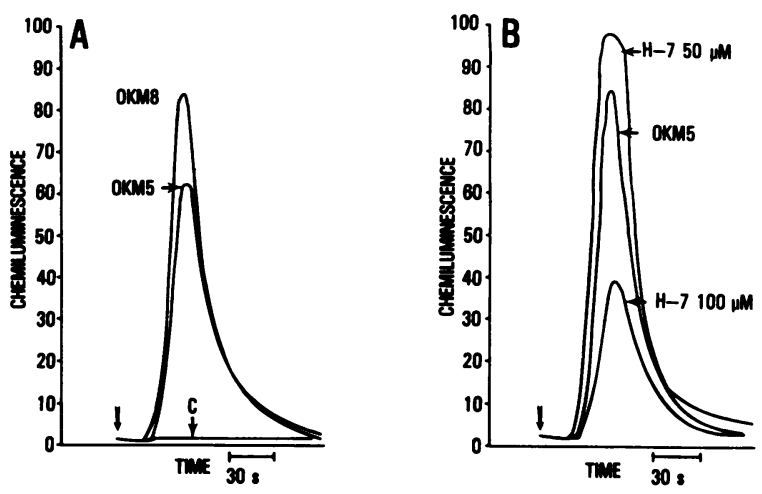

Figure 2. $(A)$ Activation of the respiratory burst in human monocytes by anti-CD36 MAbs OKM5 and OKM8. Arbitrary chemiluminescence units, amplified by adjusting the gain setting on the Lumiaggregometer, are indicated on the ordinate. The time at which MAbs $(4 \mu \mathrm{g} / \mathrm{ml})$ were added is indicated by the arrow. Control MAbs $2 \mathrm{~A} 12$ and OKM $1(C)$ did not elicit chemiluminescence in human monocytes. ( $B$ ) Modulation of MAb OKM5-induced chemiluminescence by the protein kinase $\mathrm{C}$ inhibitor $\mathrm{H}-7$. The inhibitor was added to the monocytes 5 min before adding MAb OKM5.
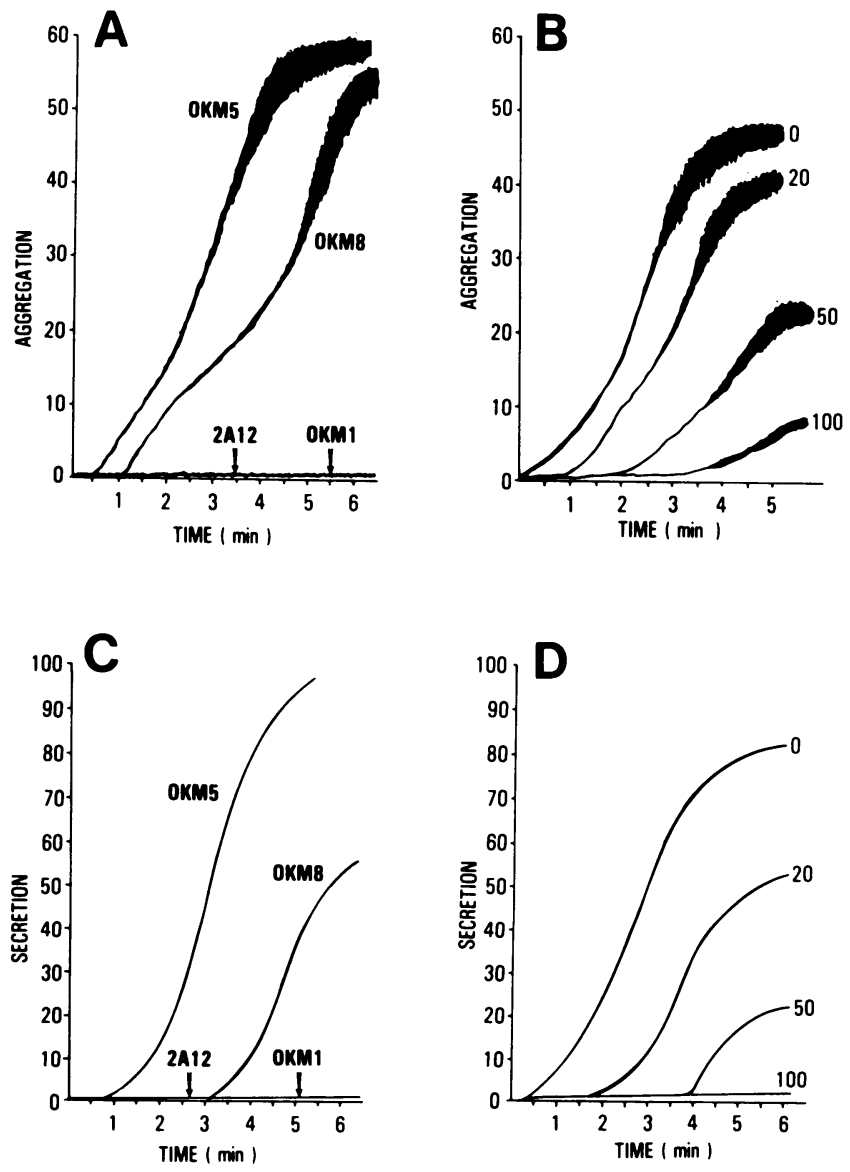

Figure 3. Activation of human platelets by anti-CD36 MAbs, and its inhibition by the protein kinase $\mathrm{C}$ inhibitor $\mathrm{H}-7$. In $(A)$ and $(C)$ platelet-rich plasma was incubated with MAbs OKM5 and OKM8 (4 $\mu \mathrm{g} / \mathrm{ml})$ or control MAbs $2 \mathrm{~A} 12$ and OKM1 $(10 \mu \mathrm{g} / \mathrm{ml})$ added at time 0 . In $(B)$ and $(D)$ platelet-rich plasma was incubated with OKM5 alone (0), or with 20,50 , or $100 \mu \mathrm{M} \mathrm{H}-7$ added 5 min before addition of OKM5 $(4 \mu \mathrm{g} / \mathrm{ml})$. Curves are representative of three separate experiments. 
duced stimulation rather than from agglutination. Platelet activation appeared to be calcium dependent, since both EDTA and a calcium channel blocker (verapamil) abolished aggregation and secretion induced by MAb OKM5 (data not shown).

Platelet activation induced by MAb OKM5 was inhibited in a dose-dependent manner by the protein kinase $C$ inhibitor $\mathrm{H}-7$ (Fig. 3, $B$ and $D$ ) and by cholera and pertussis toxins (data not shown).

Stimulation of monocytes by IRBC. Binding of IRBC to normal human monocytes stimulated the respiratory burst as measured by both NBT reduction (Table I) and chemiluminescence (Fig. 4). As previously reported (8), activation of the respiratory burst occurred in the absence of detectable phagocytosis of IRBC. IRBC-induced NBT reduction was inhibited by $\mathrm{H}-7(52.6 \pm 6.1 \%)$, cholera toxin $(59.8 \pm 4.1 \%)$, and pertussis toxin $(49.4 \pm 4.0 \%)$, similar to the inhibition by these agents of MAb OKM5-induced NBT reduction (Fig. $1 B$ ).

Cytoadherence requires expression on the surface of IRBC of a ligand that is removed by treatment with trypsin (12). IRBC-induced chemiluminescence did not occur when IRBC were pretreated with trypsin (Fig. 4).

Electron-dense knobs on the IRBC surface appeared to be the sites of attachment of IRBC to monocytes (Fig. $5 \mathrm{~A}$ ), similar to observations with endothelial cells $(15,16,42)$. The B1 1 clone of $P$. falciparum does not induce knobs on IRBC (32) and did not bind to monocytes (Table I). Electron microscopy using a cytochemical method for localizing hydrogen peroxide at juxtaposed cell membranes $(34,35)$ corroborated the results presented here and elsewhere $(8,43)$, documenting a role for reactive oxygen intermediates in IRBC-macrophage interactions (Fig. $5 B$ ).

We have recently shown that $\mathrm{CD} 36$, purified from platelets, inhibits the binding of IRBC to endothelial cells and melanoma cells (25). Purified CD36 also inhibited both the binding of IRBC to human monocytes $(67 \pm 4.1 \%$, mean $\pm S E$, inhibition at $10 \mu \mathrm{g} / \mathrm{ml})$ and the stimulation of monocyte NBT reduction by IRBC $(66 \pm 3.2 \%$ inhibition at $10 \mu \mathrm{g} / \mathrm{ml})$, indicating that CD36 participates in monocyte-IRBC interactions in vitro.

Table I. Stimulation of monocyte NBT reduction by IRBC

\begin{tabular}{lccc}
\hline & & \multicolumn{2}{c}{ Monocytes reducing NBT } \\
\cline { 3 - 4 } $\begin{array}{c}\text { P. falciparum strain } \\
\text { (\% parasitemia) }\end{array}$ & $\begin{array}{c}\text { Monocytes with } \\
\text { Z1 IRBC bound }\end{array}$ & $\begin{array}{c}\text { Monocytes with } \\
\text { Z1 IRBC bound }\end{array}$ & $\begin{array}{c}\text { Monocytes with } \\
\text { no IRBC bound }\end{array}$ \\
\hline & $\%$ & \multicolumn{2}{c}{$\%$} \\
P18(3.3) & $65.6 \pm 8.4^{*}$ & $57.9 \pm 3.6$ & $3.7 \pm 1.6$ \\
$11 G(7.5)$ & $55.9 \pm 8.1$ & $49.5 \pm 4.1$ & ND \\
E8 (6.8) & $24.6 \pm 4.1$ & $51.0 \pm 3.0$ & $8.5 \pm 1.1$ \\
B11 (10.0) & 0 & NA & $13.7 \pm 6.3$ \\
Uninfected & 0 & NA & $10.8 \pm 6.6$
\end{tabular}

Monocytes attached to coverslips were incubated with NBT and IRBC that varied in their cytoadherence properties. Stained coverslips were counted to determine the percentage of monocytes binding at least one IRBC. Monocytes with and without adherent IRBC were counted separately to determine the percentage of monocytes reducing NBT.

* Mean \pm SD $(n=3-6)$.

‡NA, not applicable.

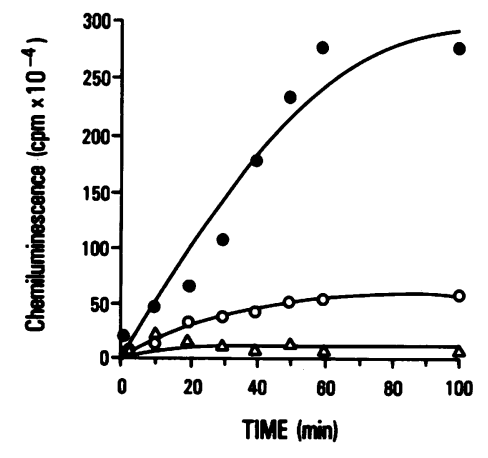

Figure 4. Stimulation of monocyte chemiluminescence by IRBC. Monocytes were incubated with uninfected erythrocytes $(\triangle), \mathrm{K}+$ $\operatorname{IRBC}(\bullet)$, or K+ IRBC pretreated with trypsin $(O)$. Data points represent the average of duplicate samples.

Binding of IRBC to CD36 on platelets. Previous studies have shown that human platelets are activated when incubated with a suspension of IRBC (26). Platelet activation could result from either soluble products of IRBC or from direct cell-cell contact. When incubated with a mixture of infected and uninfected erythrocytes attached to coverslips, fixed human platelets adhered specifically to K+ IRBC (Fig. 6), but not to uninfected erythrocytes or K- IRBC. An average of $82 \pm 5.5 \%$, mean $\pm S D, K+$ IRBC bound at least one platelet, but only $2.3 \pm 1.5 \%$ of $\mathrm{K}-$ IRBC bound at least one platelet. Platelets were not observed bound to uninfected erythrocytes. Binding of platelets to IRBC was inhibited by soluble CD36 $(80 \pm 3.6 \%$, mean $\pm \mathrm{SE}$, inhibition by $10 \mu \mathrm{g} / \mathrm{ml}$ ). These data suggest that CD36 participates in platelet-IRBC interactions in vitro.

\section{Discussion}

Our interpretation of the data presented in this study is that CD36 is a membrane receptor on monocytes and platelets, and triggering of this receptor by MAbs or IRBC results in activation of these cells. The conclusion that IRBC ligand(s) interacting with the CD36 receptor results in activation of monocytes and platelets is based on a synthesis of various pieces of data. (a) IRBC induce activation of monocytes and platelets and, at least for monocytes, this activation requires the presence of trypsin-sensitive ligand(s) on K+ IRBC. (b) Activation of monocytes and platelets is receptor mediated, since it can be prevented by inhibitors of second messengers. (c) CD36 is a receptor. It binds to IRBC with receptor-like specificity (25), and triggering of CD36 results in signal transduction. (d) Soluble CD36 inhibits the binding of IRBC to monocytes and platelets and inhibits the activation of monocytes by IRBC.

The natural ligand for the CD36 receptor is not known. It seems unlikely that this receptor evolved primarily to interact with IRBC. Secretory products of human monocytes can kill intracellular $P$. falciparum parasites in vitro (8) and may provide some protection against malaria, but CD36 is also expressed on platelets, endothelial cells, erythroblasts, and various neoplastic cell lines $(9,10,37,44-47)$, and it is not obvious how the interaction of IRBC with these cells would provide selective advantage to the host. Both thrombospondin and collagen bind specifically to the CD36 molecule (48-50), suggesting that CD36 may play a role in cell-cell and cell-matrix interactions.

The observations that CD36 is involved in the interaction of IRBC with monocytes and platelets, and that both IRBC and MAbs directed against the CD36 receptor cause similar 

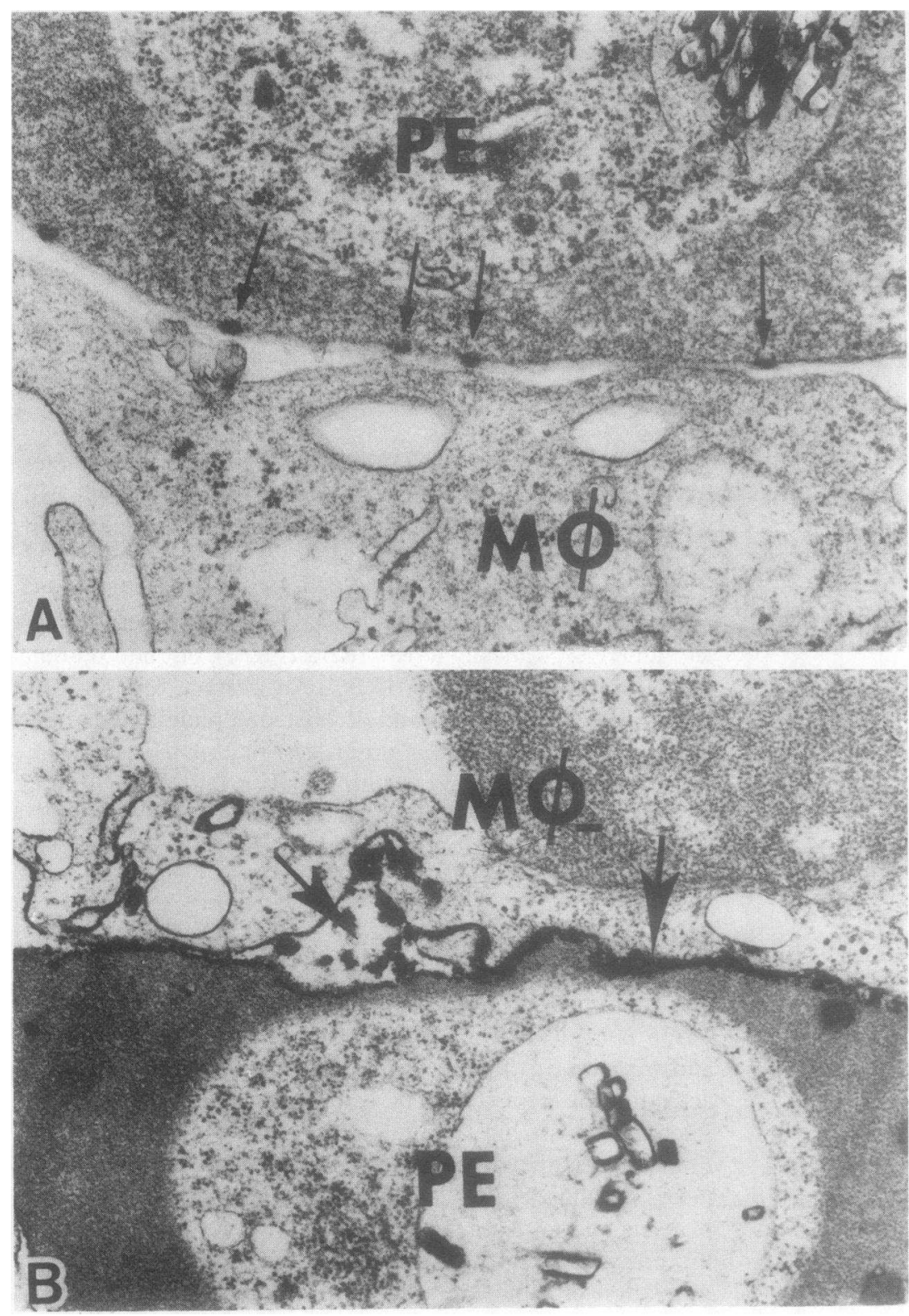

Figure 5. (A) Electron micrograph illustrating cytoadherence of an erythrocyte infected with the FCR-3 strain of $P$. falciparum $(P E)$ to a human monocyte $(M \phi)$. Electron-dense knobs on the infected erythrocyte surface (arrows) appear to be the points of attachment to the monocyte. $\times 30,000$. (B) Ultrastructural cytochemical localization of reactive oxygen intermediates. The electron-dense precipitates (arrows) indicate the presence of hydrogen peroxide in the space between the cytoadherent parasitized erythrocyte and the monocyte. $\times 30,000$. activation of these cells, suggests that both the IRBC ligand that interacts with CD36 and the antibody combining site of MAbs OKM5 and OKM8 may have a similar three-dimensional configuration. In immunofluorescence and RIA MAbs OKM5 and OKM8 competitively inhibit the binding of one another (37; Ockenhouse, C. F., unpublished observations). The minor differences in the magnitude of platelet and monocyte activation by MAbs OKM5 and OKM8 (Figs. 2 and 3) suggest that these two antibodies may have different affinities, or may bind to nonidentical but overlapping epitopes. Additional studies with other anti-CD36 MAbs and Fab fragments may help to clarify these possibilities.

Activation of monocytes by IRBC may play a role in the immunopathology of falciparum malaria. Cells of the mononuclear phagocyte lineage are frequently found in areas of parasite sequestration, such as in the lungs, bone marrow, liver, spleen, and placenta. Upon activation, monocytes release a variety of secretory products including IL-1, TNF, and reactive oxygen intermediates (51). Reactive oxygen intermediates induce lipid peroxidation, the products of which, especially aldehydes, are toxic to tissues (52). These toxic aldehydes may cause tissue damage at locations remote from the site of their production, and may be involved in such diverse pathological phenomena of malaria as adult respiratory distress syndrome, anemia, and spontaneous abortion. Products of mononuclear phagocytes, including TNF and reactive oxygen intermediates, have been shown to be important mediators of pathological changes in murine models of malaria $(22,53)$.

By interaction with IRBC, CD36 on platelets may also play a role in the thrombocytopenia that occurs commonly in patients with malaria. Human platelets express the CD36 surface antigen and can be activated by anti-CD36 MAbs, including MAb OKM5 which binds with high affinity to GPIV and stimulates platelet activation with increased expression of the fibrinogen receptor GPIIbIIIa (54). In addition, platelets from patients with falciparum malaria are activated by concentra- 


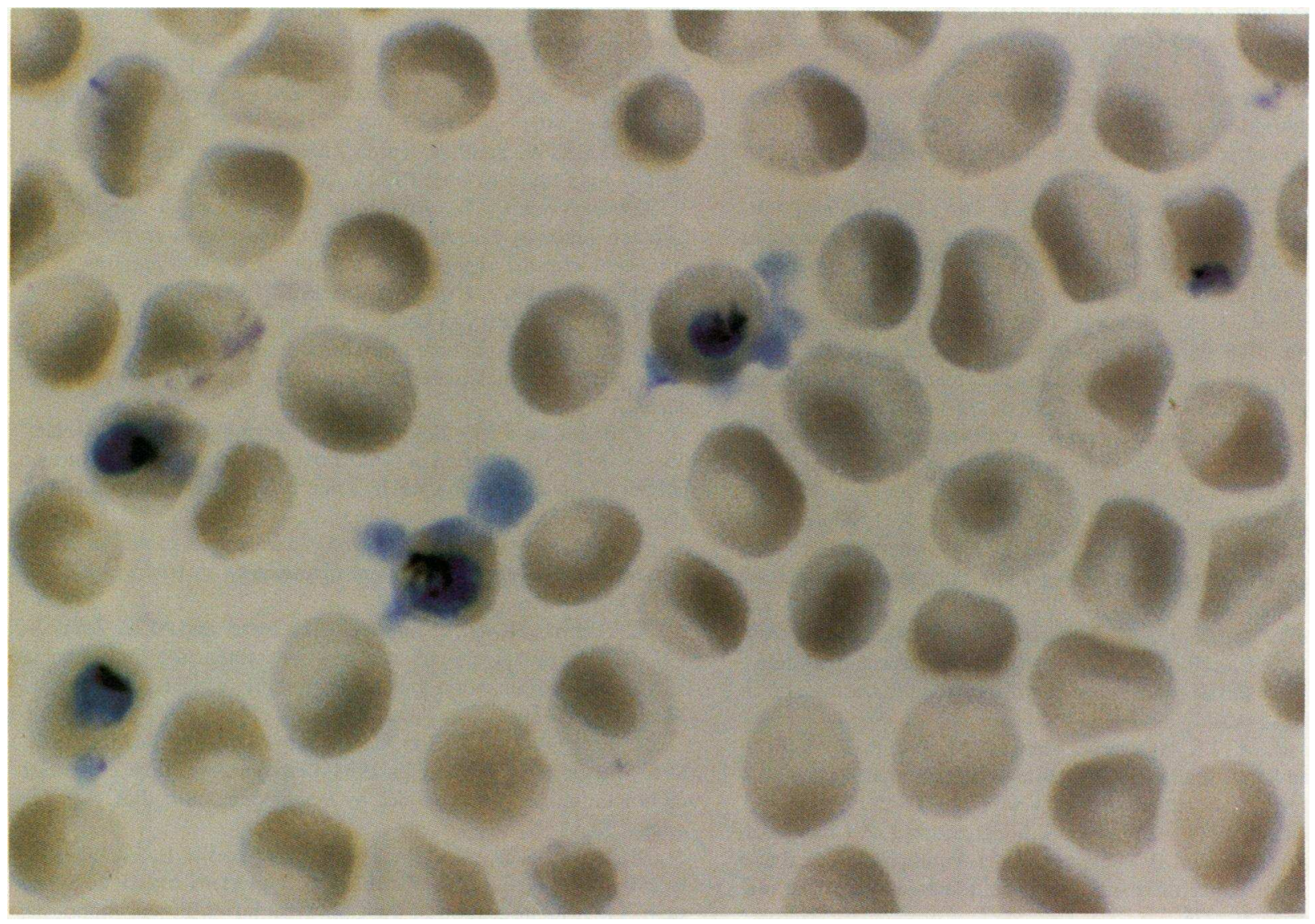

Figure 6. Binding of platelets to IRBC.

tions of ADP that do not activate normal human platelets (55, 56). Normal human platelets incubated with cultures of freshly isolated $P$. falciparum IRBC are aggregated when stimulated with subaggregating concentrations of known platelet agonists (26). Other factors must also contribute to thrombocytopenia in malaria, since thrombocytopenia occurs in malaria caused by other plasmodial species that do not induce expression of IRBC ligands binding to CD36.

Although our study focused on the relationship between expression of CD36 on platelets and monocytes and their ability to be activated by IRBC, endothelial cells are the primary targets to which IRBC bind in vivo. Endothelial cells are known to participate in the regulation of a variety of homeostatic processes, including coagulation and inflammation. CD36 is expressed on human endothelial cells (9), and IRBC may activate these cells to secrete factors including AA metabolites and kinins which mediate vascular inflammatory reactions. In addition to a postulated role in the pathological changes seen during malaria, CD36 may also be activated by its natural ligand(s) to initiate responses important in inflammation, coagulation, and vascular regulation.

\section{Acknowledgments}

We thank Dr. M. Talle and Dr. G. Goldstein for providing MAbs OKM1, OKM5, and OKM8, Dr. N. Tandon and Dr. G. A. Jamieson for purified CD36, and Dr. D. Taylor for MAb89. Fig. 5 was prepared with the assistance of Dr. Michael Stewart while C. F. Ockenhouse was in the Department of Medical and Molecular Parasitology, New York University Medical Center.

\section{References}

1. Trager, W., M. A. Rudzinska, and P. C. Bradbury. 1966. The fine structure of Plasmodium falciparum and its host erythrocytes in natural malaria infections in man. Bull. WHO. 35:883-885.

2. Bignami, A., and G. Bastianelli. 1889. Observations of estivoautumnal malaria. Reforma Medica. 6:1334.

3. Craig, C. F. 1901. The Estivo-Autumnal Malarial Fevers. William Wood \& Co., New York. 1-221.

4. Spitz, S. 1946. The pathology of acute falciparum malaria. Mil. Surgeon. 99:555-572.

5. Udeinya, I. J., J. A. Schmidt, M. Aikawa, L. Miller, and I. Green. 1981. Falciparum malaria-infected erythrocytes specifically bind to cultured human endothelial cells. Science (Wash. DC). 213:555-557.

6. Schmidt, J. A., I. J. Udeinya, J. H. Leech, R. J. Hay, M. Aikawa, J. Barnwell, I. Green, and L. Miller. 1982. Plasmodium falciparum malaria: an amelanotic melanoma cell line bears receptors for the knob ligand on infected erythrocytes. J. Clin. Invest. 70:379-386.

7. Panton, L. J., J. H. Leech, L. H. Miller, and R. J. Howard. 1987. Cytoadherence of Plasmodium falciparum-infected erythrocytes to human melanoma cell lines correlates with surface OKM5 antigen. Infect. Immun. 55:2754-2758.

8. Ockenhouse, C. F., S. Schulman, and H. L. Shear. 1984. Induction of crisis forms in the human malaria parasite, Plasmodium falciparum, by interferon-activated monocyte-derived macrophages. $J$. Immunol. 133:1601-1608.

9. Barnwell, J. W., C. F. Ockenhouse, and D. M. Knowles II. 1985. 
Monoclonal antibody OKM5 inhibits the in vitro binding of Plasmodium falciparum infected erythrocytes to monocytes, endothelial, and C32 melanoma cells. J. Immunol. 135:3494-3497.

10. Ockenhouse, C. F., and J. D. Chulay. 1988. Plasmodium falciparum sequestration: evidence that OKM5 antigen (CD36) mediates cytoadherence of parasitized erythrocytes to a myelomonocytic cell line. J. Infect. Dis. 157:584-588.

11. Cranston, H. A., C. W. Boylan, G. L. Carroll, S. P. Sutera, J. R. Williams, I. Y. Gluzman, and D. J. Krogstad. 1984. Plasmodium falciparum maturation abolishes physiologic red cell deformability. Science (Wash. DC). 223:400-403.

12. David, P. H., M. Hommel, L. H. Miller, I. J. Udeinya, and L. D. Oligino. 1983. Parasite sequestration in Plasmodium falciparum malaria: spleen and antibody modulation of cytoadherence of infected erythrocytes. Proc. Natl. Acad. Sci. USA. 80:5075-5079.

13. Israeli, A., M. Shapiro, and M. A. Epros. 1987. Plasmodium falciparum malaria in an asplenic man. Trans. $R$. Soc. Trop. Med. Hyg. 81:233-234.

14. Looareesuwan, S., M. Ho, Y. Wattanagoon, N. J. White, D. A. Warrell, D. Bunnag, T. Harinasuta, and D. J. Wyler. 1987. Dynamic alteration in splenic function during acute falciparum malaria. $N$. Engl. J. Med. 317:675-679.

15. MacPherson, G. G., M. J. Warrell, N. J. White, S. Looareesuwan, and D. A. Warrell. 1985. Human cerebral malaria: a quantitative ultrastructural analysis of parasitized erythrocyte sequestration. Am. J. Pathol. 119:385-401.

16. Oo, M. M., M. Aikawa, T. Than, T. M. Aye, P. T. Myint, I. Igarashi, and W. C. Schoene. 1987. Human cerebral malaria: a pathological study. J. Neuropathol. \& Exp. Neurol. 46:223-231.

17. White, N. J., D. A. Warrell, S. Looareesuwan, P. Chanthavanich, R. E. Phillips, and P. Pongpaew. 1985. Pathophysiological and prognostic significance of cerebrospinal fluid lactate in cerebral malaria. Lancet. i:776-778.

18. Duarte, M. I. S., C. E. P. Corbett, M. Boulos, and V. Amato Neto. 1985. Ultrastructure of the lung in falciparum malaria. Am. J. Trop. Med. Hyg. 34:31-35.

19. Garnham, P. C. C. 1938. The placenta in malaria with special reference to reticuloendothelial immunity. Trans. R. Soc. Trop. Med. Hyg. 13:1-48.

20. Walter, P. R., Y. Garin, and P. Blot. 1982. Placental pathologic changes in malaria. Am. J. Pathol. 109:330-342.

21. Clark, I. A., N. H. Hunt, and W. B. Cowden. 1986. Oxygen-derived free radicals in pathogenesis of parasitic disease. Adv. Parasitol. 25:1-44.

22. Clark, I. A., W. B. Cowden, G. A. Butcher, and N. H. Hunt. 1987. Possible roles of tumor necrosis factor in the pathology of malaria. Am. J. Pathol. 129:192-199.

23. Shaw, S. 1987. Characterization of human leukocyte differentiation antigens. Immunol. Today. 8:1-3.

24. Tandon, N. N., R. H. Lipsky, W. H. Burgess, and G. A. Jamieson. 1989. Isolation and characterization of platelet glycoprotein IV (CD36). J. Biol. Chem. 264:7570-7575.

25. Ockenhouse, C. F., N. N. Tandon, C. Magowan, G. A. Jamieson, and J. D. Chulay. 1989. Identification of a platelet membrane glycoprotein as a falciparum malaria sequestration receptor. Science (Wash. DC). 243:1469-1471.

26. Inyang, A. L., O. Sodeinde, D. T. Okpako, and E. M. Essien. 1987. Platelet reactions after interaction with cultured Plasmodium falciparum infected erythrocytes. Br. J. Haematol. 66:375-378.

27. Graves, P. M., R. Carter, J. S. Keystone, and D. C. Seeley, Jr. 1984. Drug sensitivity and isoenzyme type in cloned lines of Plasmodium falciparum. Am. J. Trop. Med. Hyg. 33:212-219.

28. Jensen, J. B., and W. Trager. 1978. Plasmodium falciparum in culture: establishment of additional strains. Am. J. Trop. Med. Hyg. 27:743-746.

29. Hommel, M., P. H. David, and L. G. Oligino. 1983. Surface alterations of erythrocytes in Plasmodium falciparum malaria. Anti- genic variation, antigenic diversity, and the role of the spleen. J. Exp. Med. 157:1137-1148.

30. Chulay, J. D., J. D. Haynes, and C. L. Diggs. 1981. Inhibition of in vitro growth of Plasmodium falciparum by immune serum from monkeys. J. Infect. Dis. 144:270-278.

31. Trager, W., and J. B. Jensen. 1976. Human malaria parasites in continuous culture. Science (Wash. DC). 193:673-675.

32. Magowan, C., W. Wollish, L. Anderson, and J. Leech. 1988. Cytoadherence by Plasmodium falciparum-infected erythrocytes is correlated with the expression of a family of variable proteins on infected erythrocytes. J. Exp. Med. 168:1307-1320.

33. Peden, D., K. Van Dyke, G. Pekoe, and V. Castranova. 1983. Temporal sequence of chemiluminescence and aggregation of human neutrophils and platelets after stimulation by arachidonic acid. Microchem. J. 28:91-98.

34. Briggs, R. T., D. B. Drath, M. L. Karnovsky, and M. J. Karnovsky. 1975. Localization of NADH oxidase on the surface of human polymorphonuclear leukocytes by a new cytochemical method. J. Cell Biol. 57:566-586.

35. Seim, S., and T. Espevik. 1983. Toxic oxygen species in monocyte-mediated antibody-dependent cytotoxicity. J. Reticuloendothel. Soc. 33:417-428.

36. Feinman, R. D., J. Lubowsky, I. Charo, and M. P. Zabinski. 1977. The lumi-aggregometer: a new instrument for simultaneous measurement of secretion and aggregation by platelets. J. Lab. Clin. Med. 90:125-129.

37. Talle, M. A., P. E. Rao, E. Westberg, N. Allegar, M. Makowski, R. S. Mittler, and G. Goldstein. 1983. Patterns of antigenic expression on human monocytes as defined by monoclonal antibodies. Cell. Immunol. 78:83-99.

38. Wright, S. D., P. E. Rao, W. C. VanVoorhis, L. S. Craigmyle, K. Iida, M. A. Talle, E. F. Westburg, G. Goldstein, and S. C. Silverstein. 1983. Identification of the C3bi receptor of human monocytes and macrophages by using monoclonal antibodies. Proc. Natl. Acad. Sci. USA. 80:5699-5703.

39. Tauber, A. I. 1987. Protein kinase $C$ and the activation of the human neutrophil NADPH-oxidase. Blood. 69:711-720.

40. Clark, R. B., J. T. Love, D. Sgri, E. G. Lingenheld, and R. I. Sha'afi. 1987. The protein kinase $\mathrm{C}$ inhibitor, $\mathrm{H}-7$, inhibits antigenand IL-2-induced proliferation of murine T cell lines. Biochem. Biophys. Res. Commun. 145:666-672.

41. Snyderman, R., C. D. Smith, and M. W. Verghese. 1986. Model for leukocyte regulation by chemoattractant receptors: roles of a guanine nucleotide regulatory protein and polyphosphoinositide metabolism. J. Leukocyte Biol. 40:785-800.

42. Luse, S. A., and L. H. Miller. 1971. Plasmodium falciparum malaria: ultrastructure of parasitized erythrocytes in cardiac vessels. Am. J. Trop. Med. Hyg. 20:655-660.

43. Makimura, S., V. Brinkmann, H. Mossmann, and H. Fischer. 1982. Chemiluminescence response of peritoneal macrophages to parasitized erythrocytes and lysed erythrocytes from Plasmodium berghei-infected mice. Infect. Immun. 37:800-804.

44. Knowles, D. M. II., B. Tolidjian, C. Barboe, V. Dagati, M. Grimes, and L. Chess. 1984. Monoclonal anti-human monocyte antibodies OKM1 and OKM5 possess distinctive tissue distribution. $J$. Immunol. 132:2170-2174.

45. Buckley, P. J., M. R. Smith, M. F. Braverman, and S. A. Dickson. 1987. Human spleen contains phenotypic subsets of macrophages and dendritic cells that occupy discrete microanatomic locations. Am. J. Pathol. 128:505-520.

46. Fukuda, Y., H. Nagura, M. Imoto, and Y. Koyama. 1986. Immunohistochemical studies on structural changes of the hepatic lobules in chronic liver disease. Am. J. Gastroenterol. 81:1149-1155.

47. Kieffer, N., A. Bettaieb, C. Legrand, W. Vainchenker, J. Breton-Gorius, and L. Edelman. 1987. Immunochemical identification of the $88 \mathrm{KD}$ platelet glycoprotein IV on human erythroid progenitor cells. Blood. 70(Suppl):156A. (Abstr.) 
48. Asch, A. S., J. Barnwell, R. L. Silverstein, and R. L. Nachman. 1987. Isolation of the thrombospondin membrane receptor. J. Clin. Invest. 79:1054-1061.

49. Tandon, N. N., A. Hines, and G. A. Jamieson. 1985. Role of glycoprotein IV in collagen-induced platelet aggregation. Blood. 66(Suppl):1148A. (Abstr.)

50. Tandon, N., U. Kralisz, and G. A. Jamieson. 1989. Identification of glycoprotein IV (CD36) as a primary receptor for platelet-collagen adhesion. J. Biol. Chem. 264:7576-7583.

51. Nathan, C. F. 1987. Secretory products of macrophages. $J$. Clin. Invest. 79:319-326.

52. Clark, I. A., N. H. Hunt, and W. B. Cowden. 1987. Immunopathology of malaria. In Immune Responses in Parasitic Infections: Im- munology, Immunopathology, and Immunoprophylaxis. E. J. L. Soulsby, editor. CRC Press, Inc., Boca Raton, FL. 1-34.

53. Grau, G. E., L. F. Fajardo, P. F. Piguet, B. Allet, P. H. Lambert, and P. Vassalli. 1987. Tumor necrosis factor (cachectin) as an essential mediator in murine cerebral malaria. Science (Wash. DC). 237:12101212.

54. Aiken, M. L., M. H. Ginsburg, V. Byers-Ward, and E. F. Plow. 1987. A monoclonal antibody to glycoprotein IV induces platelet activation. Blood. 70(Suppl):346A. (Abstr.)

55. Essien, E. M., and M. I. Ebhota. 1983. Platelet secretory activities in acute malaria (Plasmodium falciparum) infection. Acta. Haematol. (Basel). 70:183-188.

56. Essien, E. M., and M. I. Ebhota. 1981. Platelet hypersensitivity in acute malaria (Plasmodium falciparum) infection in man. Thromb. Haemostasis. 46:547-549. 